\title{
Mn-Co-Ni-O thin films prepared by sputtering with alloy target
}

\author{
Ruifeng LI, Qiuyun FU*, Xiaohua ZOU, Zhiping ZHENG, Wei LUO, Liang YAN \\ Engineering Research Center for Functional Ceramics of Ministry of Education, School of Optical and \\ Electronic Information, Huazhong University of Science and Technology, Wuhan 430074, China
}

Received: March 20, 2019; Revised: June 20, 2019; Accepted: August 17, 2019

(C) The Author(s) 2019.

\begin{abstract}
The thin film of heat-sensitive materials has been widely concerned with the current trend of miniaturization and integration of sensors. In this work, $\mathrm{Mn}_{1.56} \mathrm{Co}_{0.96} \mathrm{Ni}_{0.48} \mathrm{O}_{4}$ (MCNO) thin films were prepared on $\mathrm{SiO}_{2} / \mathrm{Si}$ substrates by sputtering with $\mathrm{Mn}-\mathrm{Co}-\mathrm{Ni}$ alloy target and then annealing in air at different temperatures $\left(650-900{ }^{\circ} \mathrm{C}\right)$. The X-ray diffraction (XRD) and field emission scanning electron microscopy (FE-SEM) analysis indicated that the main crystalline phase of MCNO thin films was spinel crystal structure; the surface of the thin films was very dense and uniform. The electrical properties of the thin films were studied in the temperature range of $-5-50{ }^{\circ} \mathrm{C}$. The MCNO thin film with a low room temperature resistance $R_{25}$ of $71.1 \mathrm{k} \Omega$ and a high thermosensitive constant $B$ value of $3305 \mathrm{~K}$ was obtained at $750{ }^{\circ} \mathrm{C}$. X-ray photoelectron spectroscopy (XPS) analysis showed that the concentration of $\mathrm{Mn}^{3+}$ and $\mathrm{Mn}^{4+}$ cations in MCNO thin films is the highest when annealing temperature is $750{ }^{\circ} \mathrm{C}$. The complex impedance analysis revealed internal conduction mechanism of the MCNO thin film and the resistance of the thin film was dominated by grain boundary resistance.
\end{abstract}

Keywords: MCNO; thin film; sputtering; annealing

\section{Introduction}

Negative temperature coefficient (NTC) thermistors are widely used in temperature sensors, household appliances, infrared detection, and other fields due to their high sensitivity, good stability, and low price [1,2]. The Mn-Co-Ni-O system materials with spinel structure $\left(\mathrm{AB}_{2} \mathrm{O}_{4}\right)$ has become one of the most commonly used NTC thermistor materials because of its excellent negative temperature coefficient and good stability [3]. Compared with traditional bulk and thick film thermistors, the thin film materials can meet the requirements of miniaturization and integration in the

* Corresponding author.

E-mail: fuqy@mail.hust.edu.cn semiconductor industry, and have the advantages of high sensitivity, fast response, etc. It has broad application prospects in the fields of MEMS, integrated circuits, and micro-nano devices, and has become the current research hotspots of NTC thermistors [4-6].

At present, the main preparation methods of NTC thin films are radio frequency magnetron sputtering, evaporation coating, metal organic thermal decomposition, pulsed laser deposition, and so on [7-11]. The metal organic thermal decomposition method is characterized by good controllability and simple operation, but the composition and thickness of the thin film may be uneven. Pulsed laser deposition has the advantages of fast deposition speed, low deposition temperature, and uniform film preparation, but the equipment is very expensive. The thin films prepared by the magnetron sputtering have good crystallinity, high purity, good 
uniformity, and are easy to be mass-produced. However, the traditional ceramic target is easily fragmented during sputtering, resulting in the surface unevenness of the target, which affects the quality of the film, and the utilization rate of the target is low. In addition, sputtering alloy target and annealing in air can make the grain on the film surface compact and reduce defects such as voids. Therefore, based on the $\mathrm{Mn}_{1.56} \mathrm{Co}_{0.96} \mathrm{Ni}_{0.48} \mathrm{O}_{4}$ system with the lowest resistivity in bulk materials, $\mathrm{Mn}_{1.56} \mathrm{Co}_{0.96} \mathrm{Ni}_{0.48} \mathrm{O}_{4}$ (MCNO) thin films were successfully prepared by sputtering $\mathrm{Mn}_{1.56} \mathrm{Co}_{0.96} \mathrm{Ni}_{0.96}$ alloy target and annealing in air. The thin film also has spinel structure, and its surface is very compact, which is conducive to reducing room temperature resistance. The effects of annealing temperature on the microstructure and electrical properties of MCNO thin films prepared by this method were discussed, and the conductive mechanism in MCNO thin films was analyzed.

\section{Experimental}

\section{1 Material preparation}

The thin film was firstly deposited on a 2 inch $\mathrm{SiO}_{2} / \mathrm{Si}$ substrate by sputtering an $\mathrm{Mn}_{1.56} \mathrm{Co}_{0.96} \mathrm{Ni}_{0.48}$ alloy target. The deposition conditions of the NTC thin films are shown in Table 1. The 2 inch thin film was then cut into $10 \mathrm{~mm} \times 10 \mathrm{~mm}$ chips and annealed in air at 650-900 ${ }^{\circ} \mathrm{C}$ for $120 \mathrm{~min}$. The heating and cooling rates are both $5{ }^{\circ} \mathrm{C} / \mathrm{min}$. Silver finger electrodes were deposited on the thin films by evaporation. Then the thin films were placed in high and low temperature box for electrical performance testing in the range of $-5-50{ }^{\circ} \mathrm{C}$. The overall structure and plane diagram of the MCNO thin film is shown in Fig. 1.

\section{2 Characterization methods}

The crystal structure of the MCNO thin films were identified by X-ray diffraction (Empyrean, PANalytical

Table 1 Deposition conditions for NTC thin films

\begin{tabular}{cc}
\hline Sputtering condition & Parameter \\
\hline Base pressure & $<6.0 \times 10^{-4} \mathrm{~Pa}$ \\
Sputtering pressure & $2.0 \mathrm{~Pa}$ \\
Sputtering gas & $\mathrm{Ar}$ \\
Sputtering power & $100 \mathrm{~W}$ \\
Substrate temperature & $150{ }^{\circ} \mathrm{C}$ \\
\hline
\end{tabular}
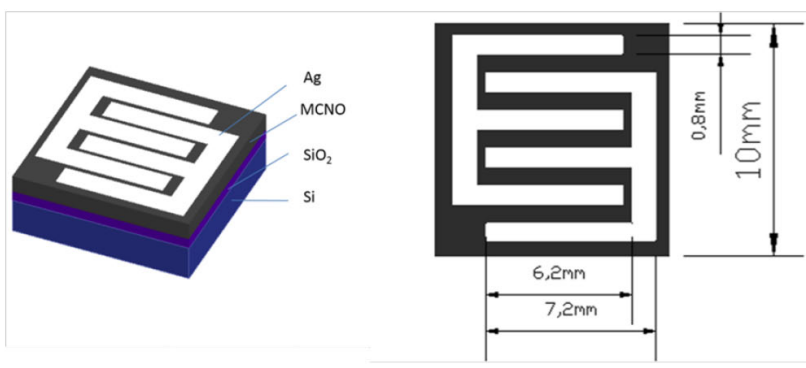

Fig. 1 Overall structure and plane diagram of $\mathrm{MCNO}$ thin film.

B.V.) with $\mathrm{Cu} \mathrm{K} \alpha$ radiation. The surface morphology and thickness of MCNO thin films were analyzed by field emission scanning electron microscopy (GeminiSEM 300-71-12). Complex impedance spectroscopy was measured over the range of $20 \mathrm{~Hz}-30 \mathrm{MHz}$ using a WK6500B impedance analyzer. The chemical states were examined by X-ray photoelectron spectroscopy (AXIS-ULTRA DLD-600W). The resistivity-temperature $(R-T)$ curves of the MCNO thin films were measured between -5 and $50{ }^{\circ} \mathrm{C}$ using high-low temperature box (G-DJS-50A) and digital multimeter (FLUKE,8808A $5-1 / 2)$.

\section{Results and discussion}

\section{1 Microstructure and surface morphology}

The XRD patterns of the MCNO thin films annealing at different temperatures of $650-900{ }^{\circ} \mathrm{C}$ are shown in Fig. 2. The MCNO thin films at different annealing temperatures all have cubic spinel structure, and the main crystal phases include $\mathrm{CoMn}_{2} \mathrm{O}_{4}, \mathrm{MnCo}_{2} \mathrm{O}_{4}$, and $\mathrm{NiMn}_{2} \mathrm{O}_{4}$. The main crystal structure of the thin films

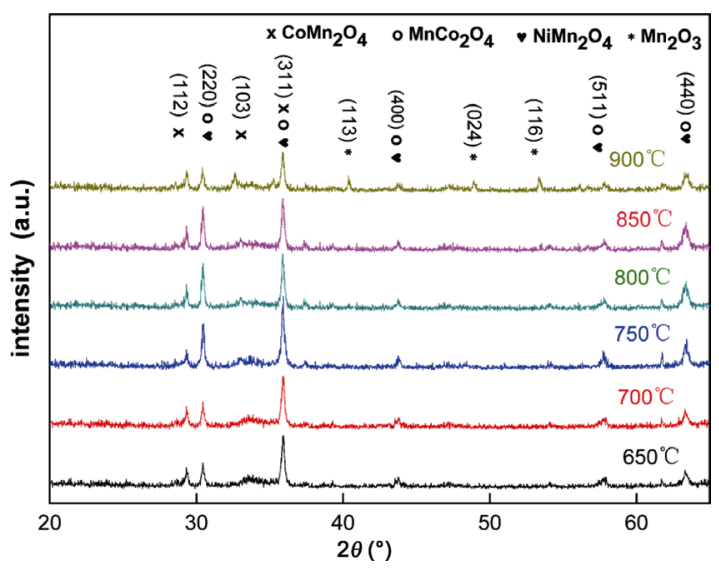

Fig. 2 XRD patterns of MCNO thin films at different annealing temperatures. 
has no obvious change. The main peak (311) of thin film is the strongest at $750{ }^{\circ} \mathrm{C}$, which indicates that the MCNO thin film is highly crystalline and oriented at annealing temperature of $750{ }^{\circ} \mathrm{C}$ [12]. When the annealing temperature reaches $850{ }^{\circ} \mathrm{C}$, the impurity phases of $\mathrm{Mn}_{2} \mathrm{O}_{3}$ and $\mathrm{MnO}_{2}$ occur due to the decomposition of the spinel structure at excessive temperature, which affects the electrical properties of the thin film [13].

The SEM surface images of MCNO thin films at different annealing temperatures are shown in Fig. 3. The surface of thin films at different annealing temperatures is relatively dense and has no obvious defects. There is no pore at the grain boundary of the thin films, which facilitates the transmission of electrons and reduces the electrical resistivity of the material. As the annealing temperature increases, the grain size of the thin films gradually increases. The average grain size of the MCNO thin films annealed at $650,700,750,800,850$, and $900{ }^{\circ} \mathrm{C}$ are $52.55,62.74$, $84.09,107.11,126.12$, and $184.15 \mathrm{~nm}$, respectively. This indicates that the increase of annealing temperature can promote the growth of grains $[14,15]$. Figure 4 is the SEM image of the thickness of 2 inch thin film measuring four boundary points (as shown in Fig. 4(e)) annealed at $750{ }^{\circ} \mathrm{C}$. The average thickness is $712,713,726$, and $719 \mathrm{~nm}$. The variance of the film thickness is $1.05 \%, 0.71 \%, 2.52 \%$, and $0.08 \%$ respectively, which indicates that the prepared film has uniform thickness and good quality. It can also be seen from Figs. 4(a)-4(d) that the thin film is tightly bound to the substrate, which is conducive to improving the electrical properties and stability of the film.

\section{2 X-ray photoelectron spectroscopy}

X-ray photoelectron spectroscopy (XPS) can identify

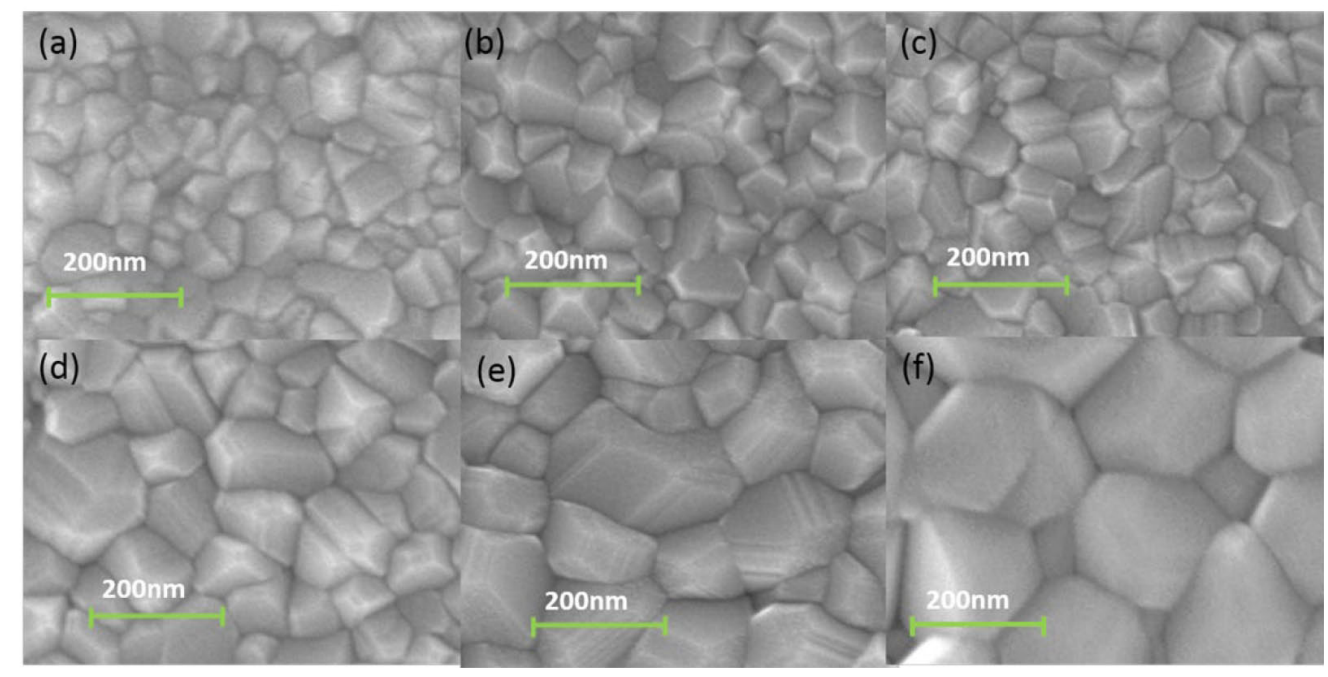

Fig. 3 FE-SEM images of MCNO thin films: surface morphology of the thin films annealed at (a) $650{ }^{\circ} \mathrm{C}$, (b) $700{ }^{\circ} \mathrm{C}$, (c) $750{ }^{\circ} \mathrm{C}$, (d) $800{ }^{\circ} \mathrm{C}$, (e) $850{ }^{\circ} \mathrm{C}$, and (f) $900{ }^{\circ} \mathrm{C}$.
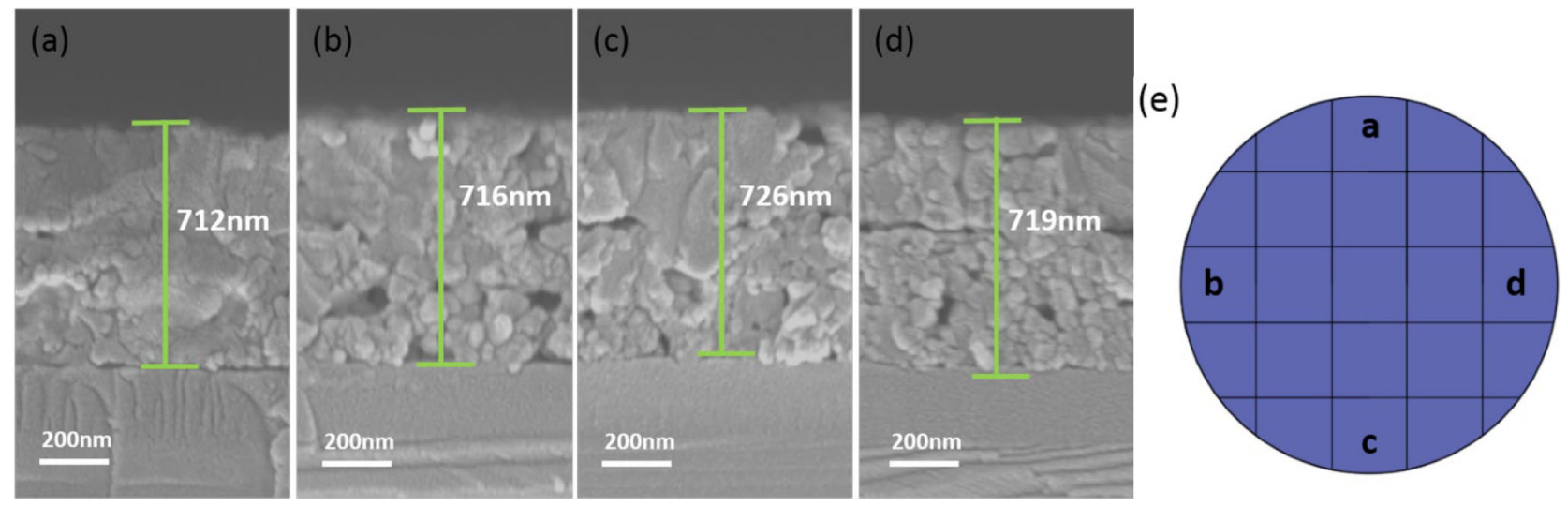

Fig. 4 Cross section of MCNO thin film annealed at $750{ }^{\circ} \mathrm{C}$. 
the structure, elements, and chemical states of the sample surface, which can be quantitatively or qualitatively analyzed [16,17]. The conductive properties of the $\mathrm{Mn}-\mathrm{Co}-\mathrm{Ni}-\mathrm{O}$ system spinel structure material are mainly affected by the concentration of $\mathrm{Mn}^{3+}$ and $\mathrm{Mn}^{4+}$ cations occupying the $\mathrm{B}$ site as following equation:

$$
\mathrm{Mn}_{\mathrm{B}}^{3+}+\mathrm{Mn}_{\mathrm{B}}^{4+} \rightleftharpoons \mathrm{Mn}_{\mathrm{B}}^{4+}+\mathrm{Mn}_{\mathrm{B}}^{3+}
$$

The variation of $\mathrm{Mn}^{2+}, \mathrm{Mn}^{3+}$, and $\mathrm{Mn}^{4+}$ cations in MCNO thin films at different annealing temperatures was investigated by XPS. The peak of the Mn $2 p_{3 / 2}$ orbital was fitted by XPS with three peaks of $\mathrm{Mn}^{2+}$ (641.0 eV), $\mathrm{Mn}^{3+}(642.28 \mathrm{eV})$, and $\mathrm{Mn}^{4+}(643.74 \mathrm{eV})$, and the results are shown in Fig. 5. The ratio of $\mathrm{Mn}^{2+}: \mathrm{Mn}^{3+}: \mathrm{Mn}^{4+}$ and $\mathrm{Mn}^{3+} / \mathrm{Mn}^{4+}$ of MCNO thin films at different annealing temperatures are shown in Table 2. As the annealing temperature increases, the concentration of $\mathrm{Mn}^{3+}$ and $\mathrm{Mn}^{4+}$ cation pairs increased first and then decreased, and the highest concentration was obtained at $750{ }^{\circ} \mathrm{C}$.

The XPS spectra of the Co $2 \mathrm{p}$ and Ni $2 \mathrm{p}$ levels are shown in Figs. 6(a) and 6(b). The Co $2 p$ spectra are dominated by two peaks located at 780.2 and $795.9 \mathrm{eV}$ in binding energy, corresponding to the Co $2 \mathrm{p}_{3 / 2}$ and Co $2 p_{1 / 2}$ spin-orbit components, respectively. The
Table 2 Ratio of $\mathrm{Mn}^{2+}: \mathrm{Mn}^{3+}: \mathrm{Mn}^{4+}$ and $\mathrm{Mn}^{3+} / \mathrm{Mn}^{4+}$ of MCNO thin films at different annealing temperatures

\begin{tabular}{ccc}
\hline Annealing temperature & $\mathrm{Mn}^{2+}: \mathrm{Mn}^{3+}: \mathrm{Mn}^{4+}$ & $\mathrm{Mn}^{3+} / \mathrm{Mn}^{4+}$ \\
\hline $700{ }^{\circ} \mathrm{C}$ & $24.74 \%: 35.04 \%: 40.02 \%$ & 0.876 \\
$750{ }^{\circ} \mathrm{C}$ & $22.78 \%: 38.71 \%: 38.51 \%$ & 1.01 \\
$800{ }^{\circ} \mathrm{C}$ & $24.69 \%: 37.48 \%: 37.83 \%$ & 0.99 \\
$850{ }^{\circ} \mathrm{C}$ & $25.34 \%: 34.76 \%: 39.90 \%$ & 0.871 \\
\hline
\end{tabular}

satellite peak at $6.3 \mathrm{eV}$ above the main Co $2 \mathrm{p}_{3 / 2}$ peak marked by an arrow in Fig. 6(a) is attributed to the contribution from $\mathrm{Co}^{2+}$ species [18]. Besides, the satellite structure related to $\mathrm{Co}^{3+}$ species was hardly detected, which means that $\mathrm{Co}^{3+}$ has not been found in the thin films. In the Ni $2 p$ spectra, $\mathrm{Ni} 2 \mathrm{p}_{3 / 2}$ and $\mathrm{Ni}$ $2 \mathrm{p}_{1 / 2}$ peaks are located at 854.6 and $872.7 \mathrm{eV}$, respectively. In the nickel-containing oxides, the $\mathrm{Ni}$ $2 p_{3 / 2}$ always shows two obvious peaks labeled as c3d9L and c3d10L2. It demonstrates that the $\mathrm{Ni}$ element exists in the form of +2 valence in all films.

In the $\mathrm{Mn}-\mathrm{Co}-\mathrm{Ni}-\mathrm{O}$ system spinel structure, the divalent cation first occupies the tetrahedral A site, and there is an empirical rule for the priority order of $\mathrm{Mn}^{2+}>\mathrm{Co}^{2+}>\mathrm{Ni}^{2+}[19]$. Based on this empirical rule, the surface valence state distribution of the MCNO thin films is shown in Table 3. The ratio of elements in the
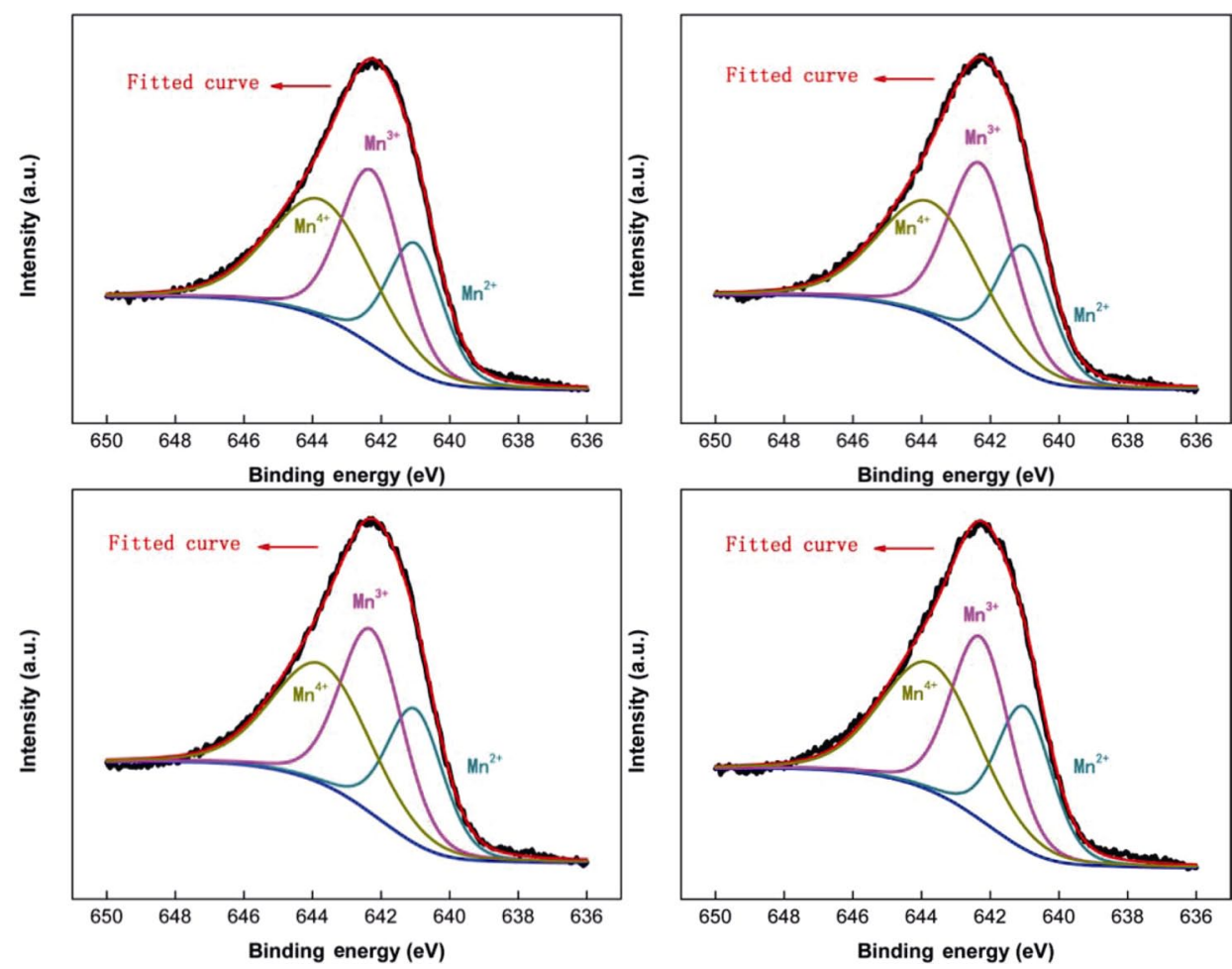

Fig. 5 XPS fitting of $\mathrm{Mn} 2 \mathrm{p}_{3 / 2}$ signals of MCNO thin films at different annealing temperatures: (a) $700{ }^{\circ} \mathrm{C}$, (b) $750{ }^{\circ} \mathrm{C}$, (c) $800{ }^{\circ} \mathrm{C}$, (d) $850{ }^{\circ} \mathrm{C}$. 

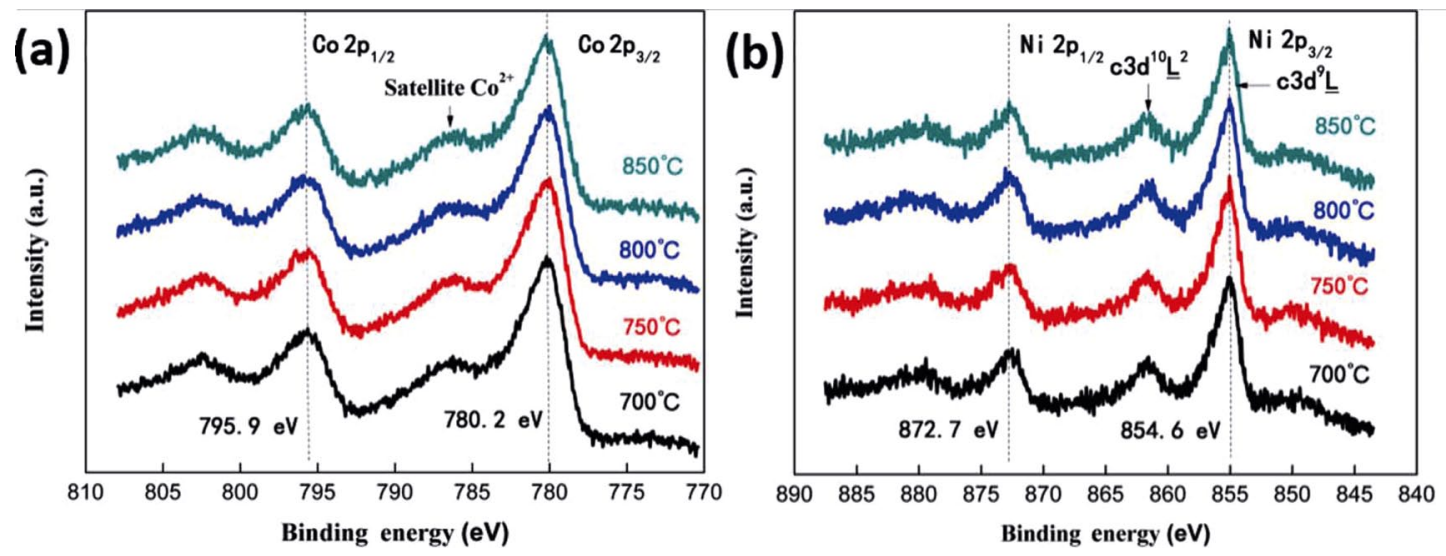

Fig. 6 XPS spectra of (a) Co 2p and (b) Ni 2p level signals of MCNO thin films at different annealing temperatures.

Table 3 Molecular formula and cation distribution of MCNO thin films at different annealing temperatures

\begin{tabular}{cll}
\hline Annealing temperature & Molecular formula & \multicolumn{1}{c}{ Cation distribution } \\
\hline $700{ }^{\circ} \mathrm{C}$ & $\mathrm{Mn}_{1.93} \mathrm{Co}_{0.81} \mathrm{Ni}_{0.26} \mathrm{O}_{4+\delta}$ & {$\left[0.52 \mathrm{Co}^{2+} 0.48 \mathrm{Mn}^{2+}\right]_{\mathrm{A}}\left[0.26 \mathrm{Ni}^{2+} 0.29 \mathrm{Co}^{2+} 0.68 \mathrm{Mn}^{3+} 0.77 \mathrm{Mn}^{4+}\right]_{\mathrm{B}} \mathrm{O}_{4+\delta}$} \\
$750{ }^{\circ} \mathrm{C}$ & $\mathrm{Mn}_{1.93} \mathrm{Co}_{0.81} \mathrm{Ni}_{0.26} \mathrm{O}_{4+\delta}$ & {$\left[0.56 \mathrm{Co}^{2+} 0.44 \mathrm{Mn}^{2+}\right]_{\mathrm{A}}\left[0.26 \mathrm{Ni}^{2+} 0.25 \mathrm{Co}^{2+} 0.75 \mathrm{Mn}^{3+} 0.74 \mathrm{Mn}^{4+}\right]_{\mathrm{B}} \mathrm{O}_{4+\delta}$} \\
$800{ }^{\circ} \mathrm{C}$ & $\mathrm{Mn}_{1.95} \mathrm{Co}_{0.77} \mathrm{Ni}_{0.28} \mathrm{O}_{4+\delta}$ & {$\left[0.52 \mathrm{Co}^{2+} 0.48 \mathrm{Mn}^{2+}\right]_{\mathrm{A}}\left[0.28 \mathrm{Ni}^{2+} 0.25 \mathrm{Co}^{2+} 0.73 \mathrm{Mn}^{3+} 0.74 \mathrm{Mn}^{4+}\right]_{\mathrm{B}} \mathrm{O}_{4+\delta}$} \\
$850{ }^{\circ} \mathrm{C}$ & $\mathrm{Mn}_{1.96} \mathrm{Co}_{0.77} \mathrm{Ni}_{0.27} \mathrm{O}_{4+\delta}$ & {$\left[0.50 \mathrm{Co}^{2+} 0.50 \mathrm{Mn}^{2+}\right]_{\mathrm{A}}\left[0.27 \mathrm{Ni}^{2+} 0.27 \mathrm{Co}^{2+} 0.68 \mathrm{Mn}^{3+} 0.78 \mathrm{Mn}^{4+}\right]_{\mathrm{B}} \mathrm{O}_{4+\delta}$} \\
\hline
\end{tabular}

MCNO thin film at different annealing temperature did not change much, but the ratio of $\mathrm{Mn}^{3+}$ and $\mathrm{Mn}^{4+}$ in the positive octahedral position changed, which laid the foundation for the analysis of electrical properties.

\section{3 Electrical properties}

The electrons in the MCNO system of spinel are in the form of small polarons, and the resistance temperature relationship of the materials is obtained by the following equation [20]:

$$
R(T)=C T^{\alpha} \exp \left(\frac{T_{0}}{T}\right)^{p}
$$

Constant $T_{0}$ is the characteristic temperature of the material, and its product with the Boltzmann constant $k_{\mathrm{B}}$ is the activation energy. $T_{0}$ is an electrical parameter corresponding to the constant $B$ value of industrial thermistors [21,22]. $\alpha$ and $p$ are temperature dependence indices of the material. When $0.25<p=$ $\alpha / 2<1$, electrons mainly jump between electronic states (intermediate states) with similar energies, which is the variable range hopping (VRH) model. When $\alpha=$ $p=1$, the hopping of electrons are mainly between nearest neighbor states, which is the nearest neighbor hopping $(\mathrm{NNH})$ model.

The $R-T$ and $\ln (R / T)-1000 / T$ curves of MCNO thin films at different annealing temperatures are shown in Figs. 7(a) and 7(b), respectively. The $R-T$ curves of all samples are exponential and the linearity of $\ln (R / T)-1000 / T$ is good, indicating that the samples all have excellent NTC thermistor characteristics. Figure 8 shows the $R_{25}$ and $B$ values of MCNO films at different annealing temperatures. The thermal constant $B$ value can be calculated by the following equation:

$$
B=\frac{T_{1} T_{2}}{T_{2}-T_{1}} \ln \frac{R_{1}}{R_{2}}
$$

As the annealing temperature increases, the $R_{25}$ of the sample decreases first and then increases, while $B_{25 / 50}$ monotonously increases with increasing annealing temperature. When the annealing temperature is $750{ }^{\circ} \mathrm{C}$, the sample reaches its minimum electrical resistance of $71.1 \mathrm{k} \Omega$ and its $B$ value is $3305 \mathrm{~K}$. Generally, in the same volume of the MCNO thin film, the larger the grain size, the less the number of insulating grain boundaries and the lower the resistance of the film. However, if the annealing temperature is too high, the grain growth will be excessively stacked, and the number of grain boundaries will increase and meanwhile the spinel phase in the MCNO thin films is decomposed into $\mathrm{Mn}_{2} \mathrm{O}_{3}$ and $\mathrm{MnO}_{2}$, which affects the conductivity of the film. Then the resistance will increase. On the other hand, the concentration of $\mathrm{Mn}^{3+}$ and $\mathrm{Mn}^{4+}$ cations in the octahedral position participating in conduction is the highest at $750{ }^{\circ} \mathrm{C}$. Therefore, when the annealing temperature is $750{ }^{\circ} \mathrm{C}$, the $R_{25}$ turning point of the thin film appears. 

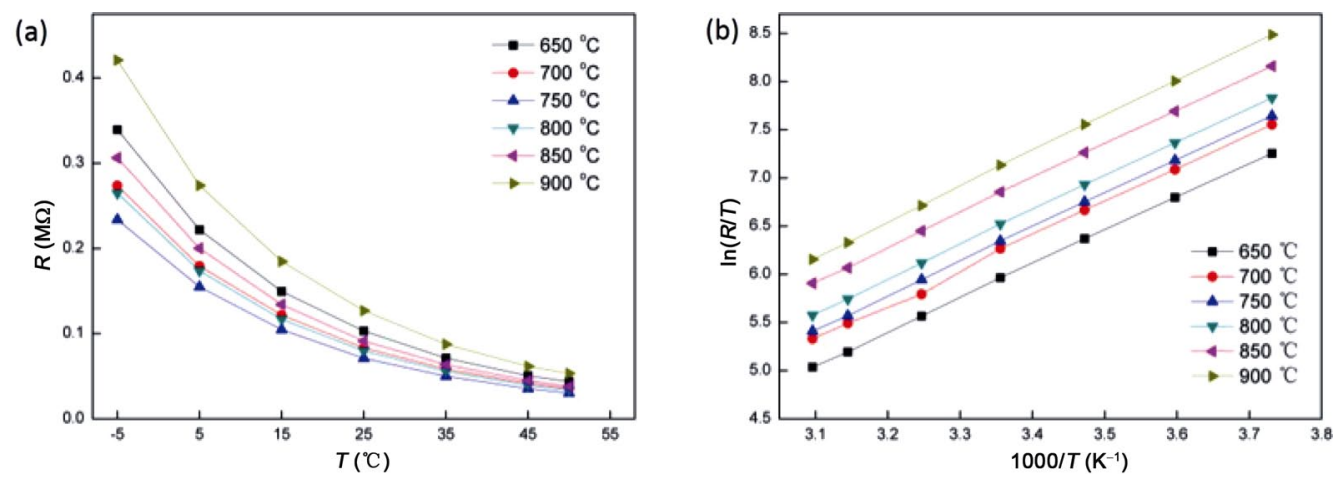

Fig. 7 (a) $R-T$, (b) $\ln (R / T)-1000 / T$ curves of $\mathrm{MCNO}$ thin films at different annealing temperatures.

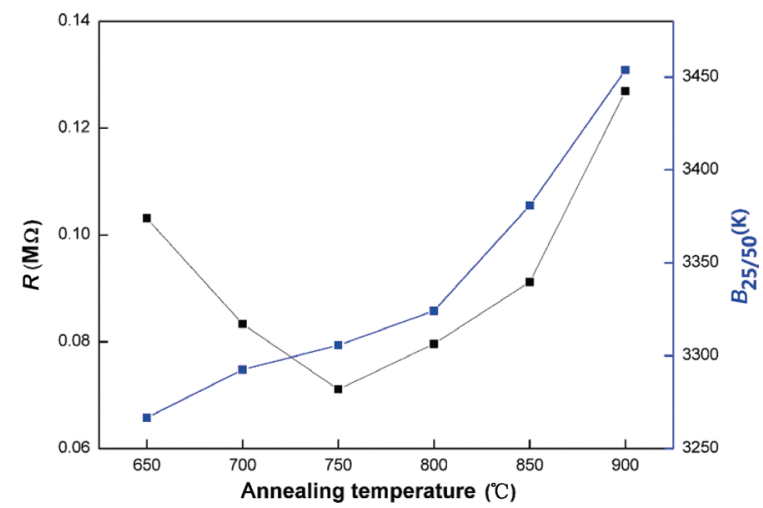

Fig. $8 R_{25}$ and $B$ values of MCNO thin films at different annealing temperatures.

In order to further clarify the electron conduction mechanism in the MCNO thin films, the curve of $\ln W-\ln T$ is plotted as shown in Fig. 9. Shklovskii and Efros proposed a method for determining $p[11,23]$ :

$$
W=\left(\frac{1}{T}\right) \frac{\mathrm{d}(\ln R)}{\mathrm{d}(1 / T)} \approx-p\left(\frac{T_{0}}{T}\right)^{p}
$$

The slope of fitting is $p$ value. For MCNO film samples with different annealing temperatures, the $p$ values are $1.12,1.14,1.11,0.99,1.10$, and 0.95 . All $p$ values are close to 1 , which indicates that films with different annealing temperatures are consistent with the nearest neighbor hopping $(\mathrm{NNH})$ model $[2,24]$.

The MCNO thin films at different annealing temperatures were placed in a high-low temperature test box and aged at $80{ }^{\circ} \mathrm{C}$ for $240 \mathrm{~h}$. The relative resistance change was shown in Fig. 10. The ageing coefficient $(\Delta R / R)$ of MCNO thin films is gradually stabilized after $72 \mathrm{~h}$. The aging coefficient of $240 \mathrm{~h}$ are $23.56 \%, 21.60 \%, 15.91 \%, 14.78 \%, 14.23 \%$, and $13.27 \%$ for MCNO thin films annealed at 650,700 , $750,800,850$, and $900{ }^{\circ} \mathrm{C}$, respectively. The aging property of the NTC thin films is affected by cationic

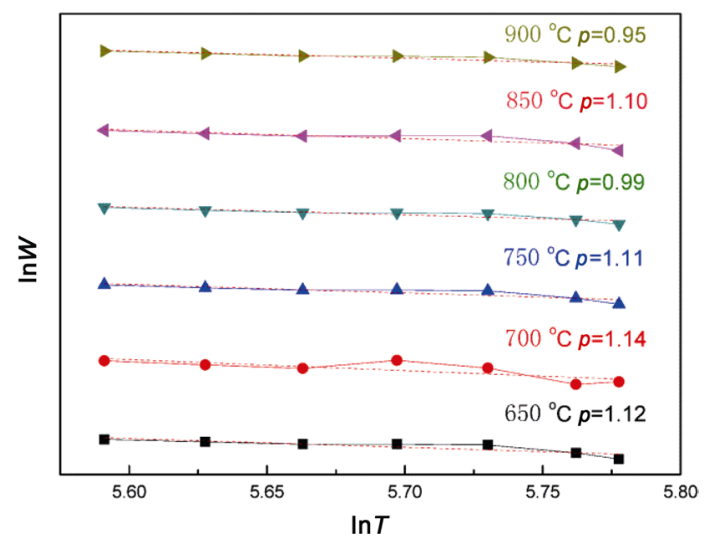

Fig. $9 \ln W-\ln T$ of MCNO thin films at different annealing temperatures.

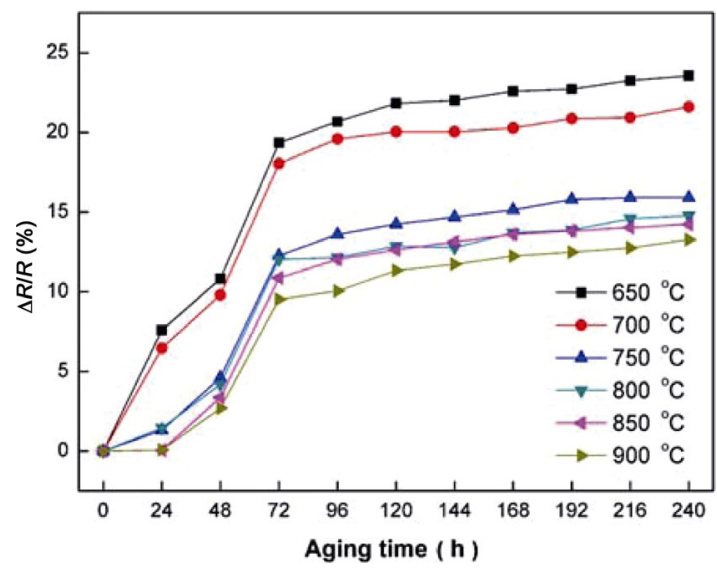

Fig. 10 Relationship between the aging values and the aging time of MCNO films at different annealing temperatures.

oxidation, and the cation at the grain boundary is more easily oxidized than in the grain [25]. As the annealing temperature increases, the grain size gradually increases, and the cation at the grain boundary decreases, so the aging property of the MCNO thin film becomes good. 


\section{4 Complex impedance spectrum}

AC impedance spectroscopy is a powerful technique for explaining the conduction and polarization processes in materials. It can analyze the grain and grain boundary conductivity of NTC materials separately [26,27]. The complex impedance spectrum of MCNO films at different annealing temperatures measured at $25{ }^{\circ} \mathrm{C}$ is shown in Fig. 11. The equivalent circuit is shown in the inset of Fig. 11, which is obtained by fitting the measurement data by software Zview 2. $R_{\mathrm{g}}$ and $R_{\mathrm{gb}}$ represent grain resistance and grain boundary resistance, and CPE is a constant phase element. The complex impedance spectra of thin films at different annealing temperatures are all shown as flattened semicircles. When the annealing temperature is $750{ }^{\circ} \mathrm{C}$, the half circle area is the smallest, indicating that the impedance is obviously smaller than other samples. And the semicircle has little change in the left intercept of the $Z^{\prime}$ axis, and the right intercept changes significantly, indicating that the grain resistance is very small and grain boundary resistance plays a dominant role $[9,28]$.

In NTC materials, electrons are excited by heat, and activation energy can be expressed by the following equation:

$$
E_{\mathrm{a}}(T)=k T\left(\frac{T_{0}}{T}\right)^{p}
$$

The curves of $\ln \left(R_{\mathrm{g}} / T\right)$ and $\ln \left(R_{\mathrm{gb}} / T\right)-1000 / T$ of film annealed at $750{ }^{\circ} \mathrm{C}$ are shown in Fig. 12. The activation of the fit shows that the conductance activation energy of the grains and grain boundaries is much lower than the long-range mobility activation

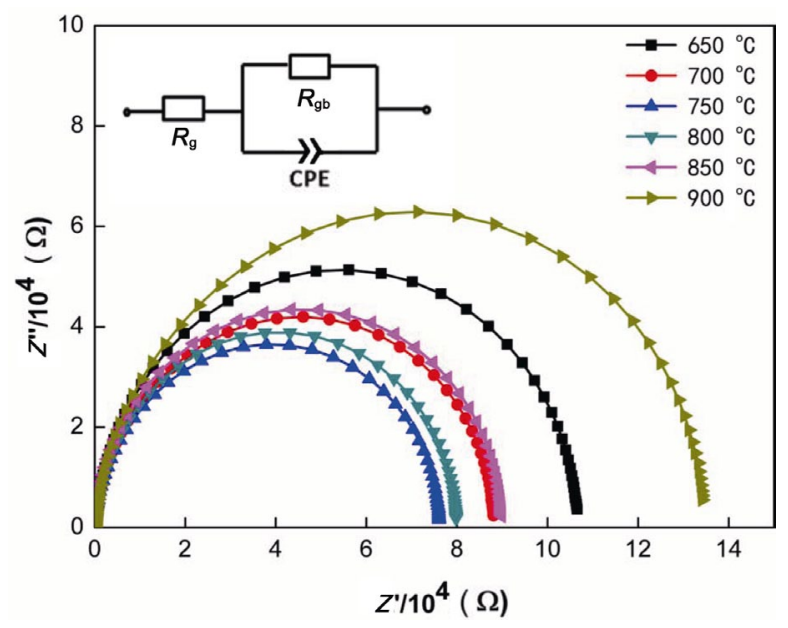

Fig. 11 Complex impedance spectroscopy of MCNO thin films with different annealing temperatures.

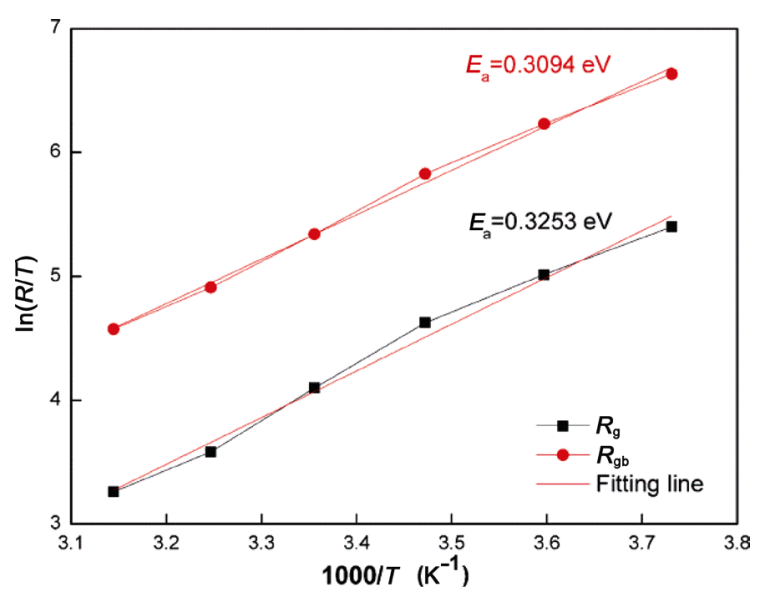

Fig. 12 Curves of $\ln \left(R_{\mathrm{g}} / T\right)$ and $\ln \left(R_{\mathrm{gb}} / T\right)-1000 / T$ of MCNO thin film with annealing at $750{ }^{\circ} \mathrm{C}$.

energy of the oxygen vacancies, so the conductance of the grains and grain boundaries is caused by electron hopping [29]. Understanding the conductive mechanism inside the NTC material will greatly help the application of NTC thin film.

\section{Conclusions}

MCNO thin films were prepared by sputtering using $\mathrm{Mn}_{1.56} \mathrm{Co}_{0.96} \mathrm{Ni}_{0.48}$ alloy target and then annealing in air. It can be seen from the XRD pattern that the MCNO thin films at different annealing temperature all have cubic spinel structures. The SEM image shows that the thin films were very dense and had no obvious defects, and the grain size gradually increased as the annealing temperature increases. The MCNO films also had good thickness uniformity. When the annealing temperature is $750{ }^{\circ} \mathrm{C}$, the MCNO film has the lowest $R_{25}(71.1 \mathrm{k} \Omega)$ and a higher $B$ value $(3305 \mathrm{~K})$. XPS analysis shows that the concentration of $\mathrm{Mn}^{3+}$ and $\mathrm{Mn}^{4+}$ cations in MCNO thin films is the highest when annealing temperature is $750{ }^{\circ} \mathrm{C}$. Through impedance analysis, it can be known that the influence of annealing temperature on room temperature resistance is mainly the effect on grain boundary resistance.

\section{Acknowledgements}

This work was supported by National Key R\&D Program of China (Grant No. 2017YFB0406405) and National Natural Science Foundation of China (Grant No. 61571203). 


\section{References}

[1] Ma C, Ren W, Wang L, et al. Structural, optical, and electrical properties of $\left(\mathrm{Mn}_{1.56} \mathrm{Co}_{0.96} \mathrm{Ni}_{0.48} \mathrm{O}_{4}\right)_{1-x}\left(\mathrm{LaMnO}_{3}\right)_{x}$ composite thin films. $J$ Eur Ceram Soc 2016, 36: 4059-064.

[2] Kong WW, Chen L, Gao B, et al. Fabrication and properties of $\mathrm{Mn}_{1.56} \mathrm{Co}_{0.96} \mathrm{Ni}_{0.48} \mathrm{O}_{4}$ free-standing ultrathin chips. Ceram Int 2014, 40: 8405-8409.

[3] Feteira A. Negative temperature coefficient resistance (NTCR) ceramic thermistors: An industrial perspective. $J$ Am Ceram Soc 2009, 92: 967-983.

[4] Zhang F, Zhou W, Ouyang C, et al. Annealing effect on the structural and electrical performance of $\mathrm{Mn}-\mathrm{Co}-\mathrm{Ni}-\mathrm{O}$ films. AIP Adv 2015, 5: 117137.

[5] Jadhav R, Kulkarni D, Puri V. Structural and electrical properties of fritless $\mathrm{Ni}\left({ }_{1-x}\right) \mathrm{Cu}_{x} \mathrm{Mn}_{2} \mathrm{O}_{4}(0 \leqslant x \leqslant 1)$ thick film NTC ceramic. J Mater Sci: Mater Electron 2010, 21: 503-508.

[6] Jagtap S, Rane S, Gosavi S, et al. Low temperature synthesis and characterization of NTC powder and its 'lead free' thick film thermistors. Microelectron Eng 2010, 87: 104-107.

[7] Zhou W, Zhang LB, Ouyang C, et al. Micro structural, electrical and optical properties of highly (220) oriented spinel $\mathrm{Mn}-\mathrm{Co}-\mathrm{Ni}-\mathrm{O}$ film grown by radio frequency magnetron sputtering. Appl Surf Sci 2014, 311: 443-447.

[8] He L, Ling ZY, Wu MY, et al. Thermal and humidity sensing behaviors of $\mathrm{Mn}_{1.85} \mathrm{Co}_{0.3} \mathrm{Ni}_{0.85} \mathrm{O}_{4}$ thin films: Effects of adjusting the surface morphology. Appl Surf Sci 2017, 410: 201-205.

[9] Kong WW, Wei W, Gao B, et al. $\mathrm{Mn}_{1.56} \mathrm{Co}_{0.96} \mathrm{Ni}_{0.48} \mathrm{O}_{4 \pm \delta}$ flexible thin films fabricated by pulsed laser deposition for NTC applications. Mat Sci Eng B 2016, 206: 39-44.

[10] Kukuruznyak DA, Moyer JG, Ohuchi FS. Improved aging characteristics of NTC thermistor thin films fabricated by a hybrid sol-gel-MOD process. $J$ Am Ceram Soc 2006, 89: 189-192.

[11] Shi Q, Ren W, Kong WW, et al. High B value Mn-Co-Ni spinel films on alumina substrate by RF sputtering. J Mater Sci: Mater Electron 2017, 28: 9876-9881.

[12] Zhou W, Xu XF, Ouyang C, et al. Annealing effect on the structural, electrical and $1 / \mathrm{f}$ noise properties of $\mathrm{Mn}-\mathrm{Co}-$ Ni-O thin films. J Mater Sci: Mater Electron 2014, 25: 1959-1964.

[13] He L, Ling ZY, Huang YT, et al. Effects of annealing temperature on microstructure and electrical properties of Mn-Co-Ni-O thin films. Mater Lett 2011, 65: 1632-1635.

[14] Ge YJ, Huang ZM, Hou Y, et al. Low temperature growth of manganese cobalt nickelate films by chemical deposition. Thin Solid Films 2008, 516: 5931-5934.

[15] Park K, Lee JK. Mn-Ni-Co-Cu-Zn-O NTC thermistors with high thermal stability for low resistance applications. Scripta Mater 2007, 57: 329-332.

[16] Han $\mathrm{H}$, Lee $\mathrm{H}$, Lim J, et al. Hopping conduction in $(\mathrm{Ni}, \mathrm{Co}, \mathrm{Mn}) \mathrm{O}_{4}$ prepared by different synthetic routes: Conventional and spark plasma sintering. Ceram Int 2017, 43: $16070-16075$.

[17] Dolla TH, Pruessner K, Billing DG, et al. Sol-gel synthesis of $\mathrm{Mn}_{x} \mathrm{Ni}_{1-x} \mathrm{Co}_{2} \mathrm{O}_{4}$ spinel phase materials: Structural, electronic, and magnetic properties. J Alloys Compd 2018, 742: 78-89.

[18] Wu J, Huang ZM, Zhou W, et al. Investigation of cation distribution, electrical, magnetic properties and their correlation in $\mathrm{Mn}_{2-x} \mathrm{Co}_{2 x} \mathrm{Ni}_{1-x} \mathrm{O}_{4}$ films. $J$ Appl Phys 2014, 115: 113703.

[19] Kong WW, Wei W, Gao B, et al. A study on the electrical properties of $\mathrm{Mn}-\mathrm{Co}-\mathrm{Ni}-\mathrm{O}$ thin films grown by radio frequency magnetron sputtering with different thicknesses. Appl Surf Sci 2017, 423: 1012-1018.

[20] Guang J, Chang AM, Xu JB, et al. Low-temperature $\left(<300{ }^{\circ} \mathrm{C}\right)$ growth and characterization of single-[100]-oriented $\mathrm{Mn}$ Co-Ni-O thin films. Mater Lett 2013, 107: 103-106.

[21] Zhang LB, Hou Y, Zhou W, et al. Investigation on optical properties of $\mathrm{NiMn}_{2} \mathrm{O}_{4}$ films by spectroscopic ellipsometry. Solid State Commun 2013, 159: 32-35.

[22] Varghese JM, Seema A, Dayas KR. Microstructural, electrical and reliability aspects of chromium doped $\mathrm{Ni}-\mathrm{Mn}-\mathrm{Fe}-\mathrm{O}$ NTC thermistor materials. Mat Sci Eng B 2008, 149: 47-52.

[23] Schmidt R, Basu A, Brinkman AW, et al. Electron-hopping modes in $\mathrm{NiMn}_{2} \mathrm{O}_{4+\delta}$ materials. Appl Phys Lett 2005, 86: 073501.

[24] Shklovskii BI, Efros AL. Percolation theory. In: Electronic Properties of Doped Semiconductors. Springer Series in Solid-State Sciences, Vol. 45. Springer Berlin Heidelberg, 1984: 94-136.

[25] Fang DL, Zheng CH, Chen CS, et al. Aging of nickel manganite NTC ceramics. J Electroceram 2009, 22: 421-427.

[26] He L, Ling ZY. Electrical conduction of intrinsic grain and grain boundary in $\mathrm{Mn}-\mathrm{Co}-\mathrm{Ni}-\mathrm{O}$ thin film thermistors: Grain size influence. J Appl Phys 2011, 110: 093708.

[27] Morrison FD, Sinclair DC, West AR. Characterization of lanthanum-doped barium titanate ceramics using impedance spectroscopy. J Am Ceram Soc 2001, 84: 531-538.

[28] He L, Ling ZY, Ling DX, et al. The microstructure and humidity sensing properties of the $\mathrm{Mn}_{3.15} \mathrm{Co}_{0.3} \mathrm{Ni}_{0.8} \mathrm{O}_{4}$ thin film with a three-dimensional nano-network structure. Ceram Int 2016, 42: 7605-7610.

[29] Sun X, Leng SL, Zhang H, et al. Electrical properties and temperature sensitivity of $\mathrm{Li} / \mathrm{Mg}$ modified $\mathrm{Ni}_{0.7} \mathrm{Zn}_{0.3} \mathrm{O}$ based ceramics. J Alloys Compd 2018, 763: 975-982.

Open Access This article is licensed under a Creative Commons Attribution 4.0 International License, which permits use, sharing, adaptation, distribution and reproduction in any medium or format, as long as you give appropriate credit to the original author(s) and the source, provide a link to the Creative Commons licence, and indicate if changes were made.

The images or other third party material in this article are included in the article's Creative Commons licence, unless indicated otherwise in a credit line to the material. If material is not included in the article's Creative Commons licence and your intended use is not permitted by statutory regulation or exceeds the permitted use, you will need to obtain permission directly from the copyright holder.

To view a copy of this licence, visit http://creativecommons.org/licenses/by/4.0/. 